\title{
Tomographic Task-Related Functional Near-Infrared Spectroscopy in Acute Sport-Related Concussion: An Observational Case Study
}

\author{
Mario Forcione ${ }^{1,2, *(\mathbb{D}}$, Antonio Maria Chiarelli ${ }^{3}{ }^{(}$, David Perpetuini ${ }^{3}\left(\mathbb{D}\right.$, David James Davies ${ }^{1,2}$, \\ Patrick $\mathrm{O}^{\prime}$ Halloran ${ }^{2}{ }^{\oplus}$, David Hacker ${ }^{4}$, Arcangelo Merla ${ }^{3}$ and Antonio Belli ${ }^{1,2}$ \\ 1 National Institute for Health Research Surgical Reconstruction and Microbiology Research \\ Centre (NIHR-SRMRC), University Hospitals Birmingham NHS Foundation Trust, Mindelsohn Way, \\ Birmingham B15 2TH, UK; daviesdj@doctors.org.uk (D.J.D.); a.belli@bham.ac.uk (A.B.) \\ 2 Neuroscience \& Ophthalmology Research Group, Institute of Inflammation \& Ageing, College of Medical \\ and Dental Sciences, University of Birmingham, Edgbaston, Birmingham B15 2TT, UK; \\ patrickohalloran@doctors.org.uk \\ 3 Imaging and Clinical Sciences, Department of Neuroscience, University G. D'Annunzio of Chieti-Pescara, \\ Institute for Advanced Biomedical Technologies, Via Luigi Polacchi 13, 66100 Chieti, Italy; \\ antonio.chiarelli@unich.it (A.M.C.); david.perpetuini@unich.it (D.P.); arcangelo.merla@unich.it (A.M.) \\ 4 Clinical Neuropsychology, University Hospitals Birmingham NHS Foundation Trust, Mindelsohn Way, \\ Birmingham B15 2TH, UK; david.hacker@uhb.nhs.uk \\ * Correspondence: mxf610@student.bham.ac.uk
}

Received: 10 July 2020; Accepted: 28 August 2020; Published: 29 August 2020

\begin{abstract}
Making decisions regarding return-to-play after sport-related concussion (SRC) based on resolution of symptoms alone can expose contact-sport athletes to further injury before their recovery is complete. Task-related functional near-infrared spectroscopy (fNIRS) could be used to scan for abnormalities in the brain activation patterns of SRC athletes and help clinicians to manage their return-to-play. This study aims to show a proof of concept of mapping brain activation, using tomographic task-related fNIRS, as part of the clinical assessment of acute SRC patients. A high-density frequency-domain optical device was used to scan 2 SRC patients, within $72 \mathrm{~h}$ from injury, during the execution of 3 neurocognitive tests used in clinical practice. The optical data were resolved into a tomographic reconstruction of the brain functional activation pattern, using diffuse optical tomography. Moreover, brain activity was inferred using single-subject statistical analyses. The advantages and limitations of the introduction of this optical technique into the clinical assessment of acute SRC patients are discussed.
\end{abstract}

Keywords: fNIRS; diffuse optical tomography; DOT; traumatic brain injury; TBI; Silent Word Generation; Symbol Search; Digit Span; WAIS-IV; return-to-play

\section{Introduction}

Sport-related concussion (SRC) is a traumatic brain injury (TBI) characterized by a functional brain impairment in the absence of abnormalities on conventional neuroimaging (i.e., computerized tomography and magnetic resonance imaging (MRI)) [1,2].

In the United States, SRC is estimated to affect a range of between 1.6 and 3.8 million participants every year, with a continuous increase of athletes participating in contact sports [3,4]. These numbers could hide a more widespread burden as concussion can be underreported, underestimated, or denied by contact-sport players $[5,6]$. 
Following SRC, there is a timeframe, called the window of vulnerability, when a second impact could result in disproportional damage to the brain [7-9]. Avoiding impacts to the head in this window is important to SRC players as they are more prone to further SRC and musculoskeletal injuries than non-SRC players, possibly due to their inability to quickly process the evolution of the game and avoid bad collisions [10-13]. Therefore, the clinical decision regarding return-to-play is a pivotal moment in the management of contact-sport patients.

Currently, the decision to return-to-play is guided by the resolution of symptoms related to SRC (e.g., headache, confusion) [1,14]. However, studies using neurocognitive testing (e.g., Immediate Post-Concussion Assessment and Cognitive Testing (ImPACT); balance tests) and neuroimaging techniques (e.g., magnetic resonance spectroscopy) questioned the resolution of the neurometabolic and functional impairments, which characterize SRC in symptom-free SRC players [15-21]. Thus, basing return-to-play decisions on symptoms alone may expose asymptomatic concussed players to a second impact before recovery is complete. In addition, McCrea et al. showed that a conservative approach, based on a symptom-free waiting period, would not necessarily result in a better outcome for players [13]. Symptom-rating scales can fail to give a complete picture of all the possible system impairments related to concussion (e.g., cognitive, vestibular, ocular-motor, hormonal), and even when these are combined with a neurological assessment (e.g., Sport Concussion Assessment Tool (SCAT)), this may result in an incomplete follow-up of all SRC components [22,23]. The limitations of clinical decisions based predominantly on symptoms highlight the need to merge clinical assessment of SRC patients with a multimodal neuromonitoring assessment to scan all the possible system impairments which can comprise SRC, in order that clinicians can manage return-to-play safely.

Task-related functional magnetic resonance imaging (fMRI) has been extensively used to map brain activation abnormalities in SRC to identify biomarkers for patient assessment [24]. However, fMRI is a complicated and expensive imaging technique which makes it challenging to apply on a large scale. The values reported by fMRI may also be inaccurate due to the programs used $[25,26]$. Finally, the modality of scanning could influence the brain activation pattern of players who are not familiar with the environment of the scanner and rules out the assessment of players who suffer from claustrophobia.

Task-related functional near-infrared spectroscopy (fNIRS) is a scalp-located neuroimaging technique that uses near-infrared light to measure changes in oxyhemoglobin $\left(\mathrm{O}_{2} \mathrm{Hb}\right)$ and deoxyhemoglobin $(\mathrm{HHb})$. These changes are indicative of neurovascular coupling occurring with neuronal activation following a neurocognitive stimulus, similar to task-related fMRI [27,28]. Diffuse optical tomography (DOT) is an extension of fNIRS which, using models of light propagation within head structures and inversion approaches, tomographically maps the neurovascular response within the cortex with a resolution of about $1 \mathrm{~cm}$ [29-31]. Comparisons between cortical brain function monitored using task-related fNIRS and fMRI showed similar results [32-35]. So far, the use of task-related fNIRS in SRC has been limited to studies in chronic SRC athletes or after at least 2 weeks from injury [36-42]. Analyses on concussed athletes a few days from injury focused on cerebrovascular dysregulation during physical tasks (e.g., breath-holding task), limiting the optical analysis to the fluctuations of the levels of hemoglobin only, without reconstructing the signal into a tomographic image [43].

This study aims to illustrate a proof of concept of recording the brain activation pattern during 3 neurocognitive tests (i.e., Silent Word Generation (SWG), Digit Span (DS) backward, Symbol Search (SS)) in SRC players, within $72 \mathrm{~h}$ from injury, using optical tomographic reconstruction. The relatively short timeframe between injury and optical assessment highlights the possibility to perform optical neuromonitoring in acute SRC athletes as part of their early clinical assessments. The methods applied and the results obtained can pave the way for further fNIRS-DOT clinical studies during the assessment of acute SRC athletes. 


\section{Results}

\subsection{Co-Registration}

The source-detector (SD) locations were co-registered on a structural MRI template, using the digitization of their positions and the subjects' fiducials (Figure 1).

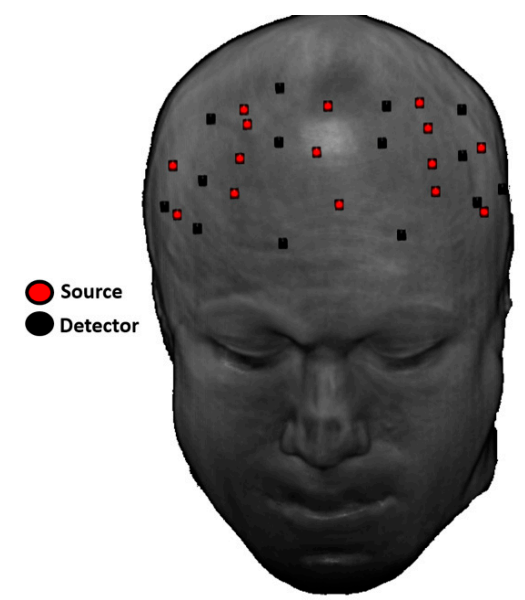

Figure 1. Illustration of the source-detector (SD) positions co-registered onto a structural magnetic resonance imaging (MRI) template.

\subsection{Oscillations of Oxyhemoglobin and Deoxyhemoglobin Levels}

As evaluated by a task-related averaging approach at a channel level, during the SWG, changes in $\mathrm{O}_{2} \mathrm{Hb}$ and $\mathrm{HHb}$ levels were compatible with a neurovascular-mediated hemodynamic response. Due to brain activation, the functional hyperemia is expected to cause a few $\mu \mathrm{M}$ increase in the concentration of $\mathrm{O}_{2} \mathrm{Hb}$, coupled with a smaller (2-3 times lower) decrease in $\mathrm{HHb}$. The opposite pattern (decrease in $\mathrm{O}_{2} \mathrm{Hb}$ and increase in $\mathrm{HHb}$ ) is often found in regions that are de-activated during the task. These oscillations happened at temporal resolutions typical of hemodynamic signals (few seconds). Examples of hemodynamic responses during the SWG are reported in Figure 2.

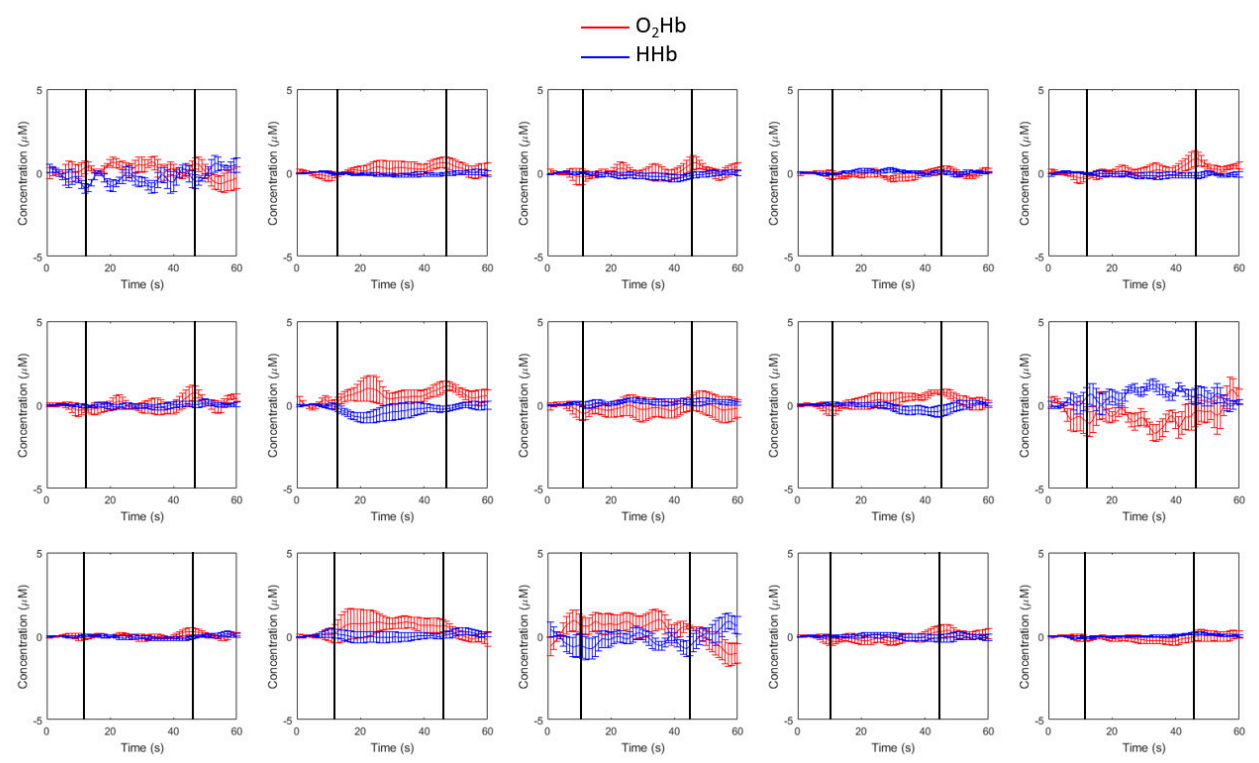

Figure 2. The 5 blocks average time-course response of changes in levels of oxyhemoglobin $\left(\mathrm{O}_{2} \mathrm{Hb}\right)$ and deoxyhemoglobin $(\mathrm{HHb})$ in a single subject for the Silent Word Generation (SWG) task. The black vertical lines represent the start and the end of the task. 


\subsection{Statistical Models Used for Single-Subject Optical Tomographic Reconstruction of the Brain Activation Pattern}

To spatially infer brain activity during SWG using the tomographic images, the General Linear Model (GLM) was used on $\mathrm{O}_{2} \mathrm{Hb}$ and $\mathrm{HHb}$ time-courses at a voxel-level [44-46]. For each voxel, the neuronal response was assumed to be a square wave locked to the stimulation, and this neuronal response was convolved with a canonical hemodynamic response function to obtain an expected pattern of hemoglobin oscillation due to brain activity. Finally, this response was correlated with the $\mathrm{O}_{2} \mathrm{Hb}$ and $\mathrm{HHb}$ time-courses in each voxel probed by the optical array to obtain a correlation coefficient and hence a statistical map (t-score map, Figure 3).
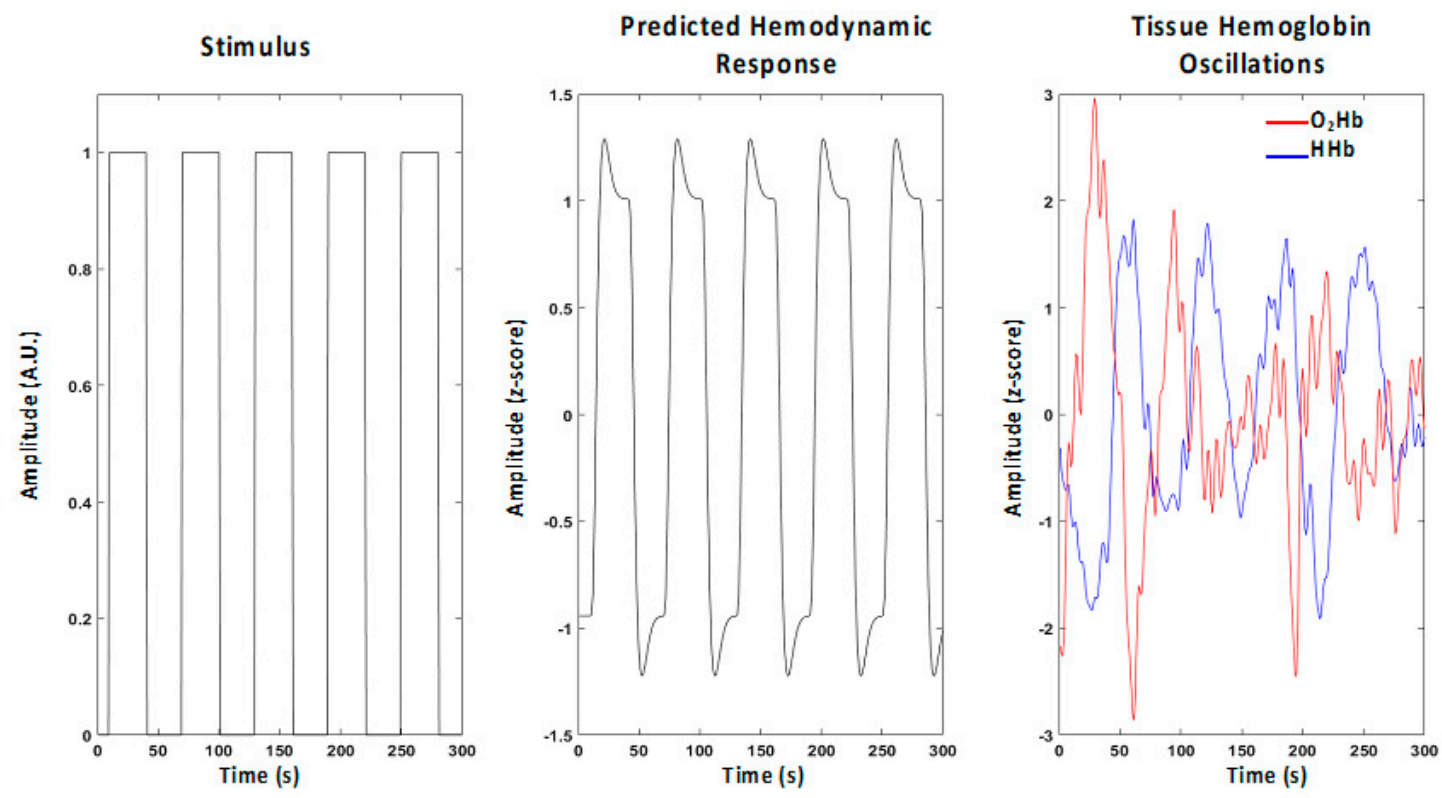

Figure 3. Scheme of application of the General Linear Model (GLM) in the analysis of the change of oxyhemoglobin $\left(\mathrm{O}_{2} \mathrm{Hb}\right)$ and deoxyhemoglobin $(\mathrm{HHb})$ levels to detect the neuronal activation.

For the DS backward and SS tests, a different approach was utilized to infer brain activity based on the assumption of increased modulations in $\mathrm{O}_{2} \mathrm{Hb}$ and $\mathrm{HHb}$ during the task compared to the resting state. The absence of a defined alternation of stimulation periods and rest impaired the utilization of the GLM approach.

During brain activity, the standard deviation of $\mathrm{O}_{2} \mathrm{Hb}$ and $\mathrm{HHb}$ was evaluated in $10 \mathrm{~s}$ integration windows during the baseline period prior to and during the tasks. Using this approach, a statistical comparison was conducted between the populations of variabilities in $\mathrm{O}_{2} \mathrm{Hb}$ and $\mathrm{HHb}$ during the baseline period and the task. Hence, this procedure allowed us to infer brain activity without having a defined stimulation pattern, with the only limitation being that it was not possible to evaluate the sign of the oscillation in response to neural activity but only the amplitude.

Figure 4 shows an example of histograms of standard deviations of $\mathrm{O} 2 \mathrm{Hb}$ for a particular voxel evaluated at a $10 \mathrm{~s}$ integration window during rest (blue bars) and the SS test (red bars). A clear increase in the average variability in $\mathrm{O}_{2} \mathrm{Hb}$ of a few $\mu \mathrm{M}$ is visible during the task, depicting plausible hemodynamic brain activity in the selected voxel. For each voxel, a statistical comparison (t-score) was performed evaluating the expected statistical difference (task vs. rest) between the average of the two populations reported in the figure. 


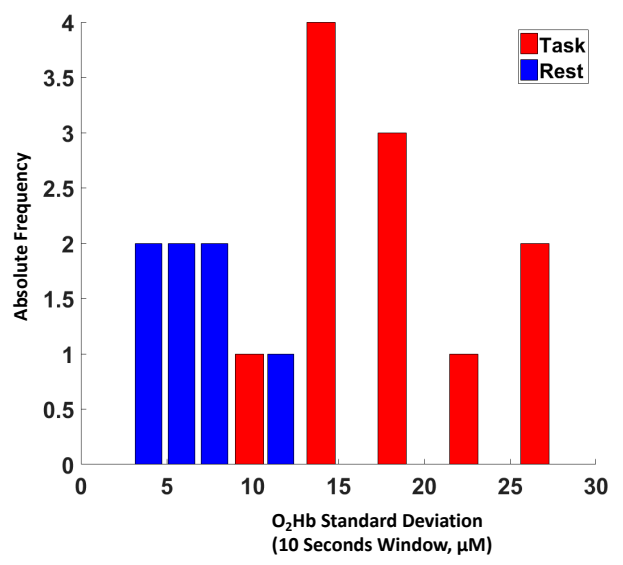

Figure 4. Example of histograms of standard deviations of oxyhemoglobin $\left(\mathrm{O}_{2} \mathrm{Hb}\right)$ for a voxel evaluated at a $10 \mathrm{~s}$ integration window during rest (blue bars) and the Symbol Search (SS) test (red bars). A clear increase in the average variability in $\mathrm{O}_{2} \mathrm{Hb}$ of a few $\mu \mathrm{M}$ is visible during the task, depicting plausible hemodynamic brain activity in the selected voxel.

\subsection{Brain Activation Patterns Measured}

fNIRS-DOT statistical parametric maps for SWG, SD, and SS were performed for the two patients and the two hemoglobin forms $\left(\mathrm{O}_{2} \mathrm{Hb}\right.$ and $\left.\mathrm{HHb}\right)$. Moreover, they were reported in regions where the spatial sensitivity of the optical array was sufficient (up to an attenuation of the average optical sensitivity of 1000 times) (Figures 5-7).

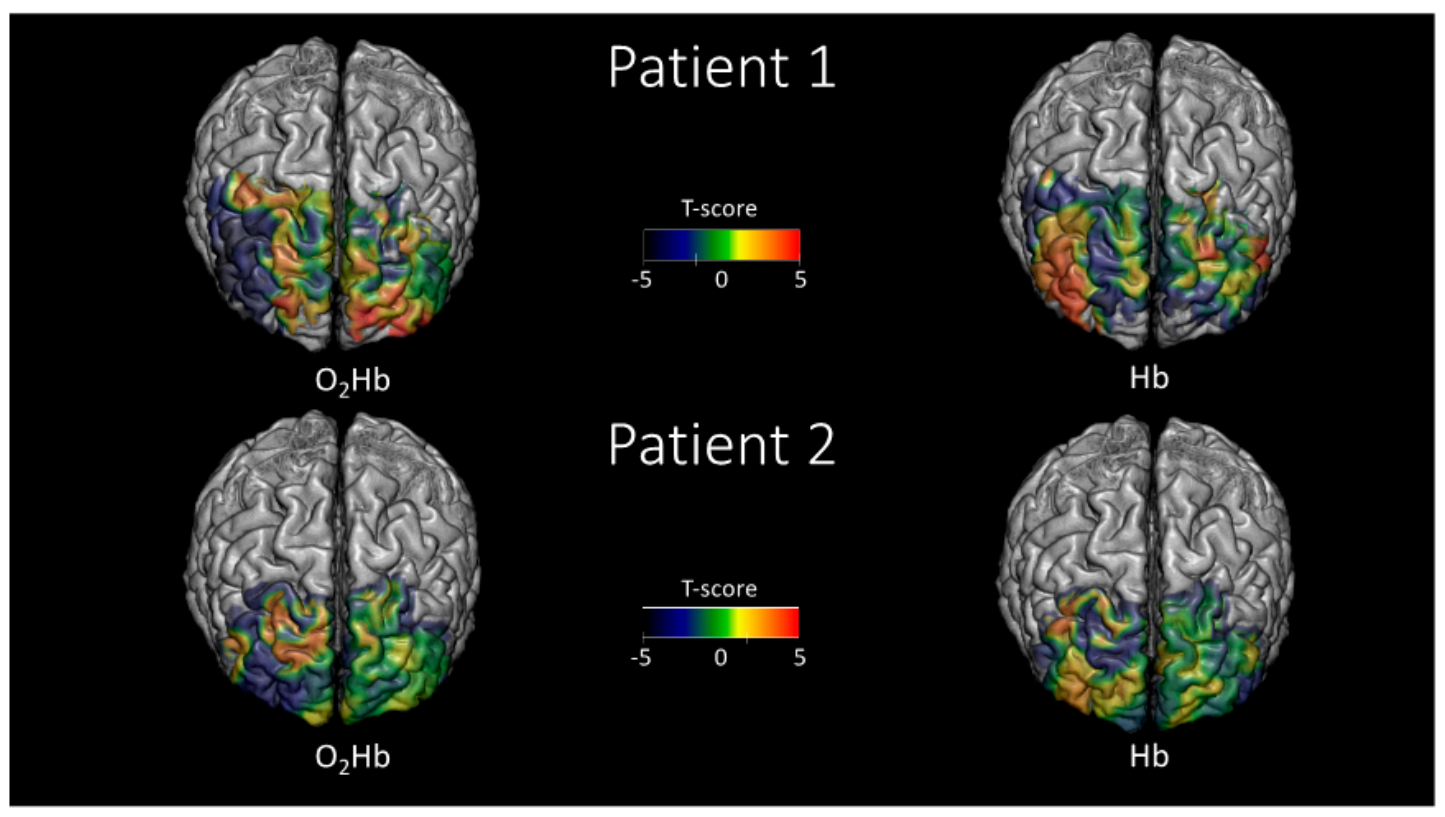

Figure 5. Statistical parametric maps (t-scores) evaluated employing the functional near-infrared spectroscopy-diffuse optical tomography (fNIRS-DOT) analysis and the General Linear Model (GLM) approach during the Silent Word Generation (SWG). The maps are reported in regions where the spatial sensitivity of the optical array was sufficient (up to an attenuation of the average optical sensitivity of 1000 times). 


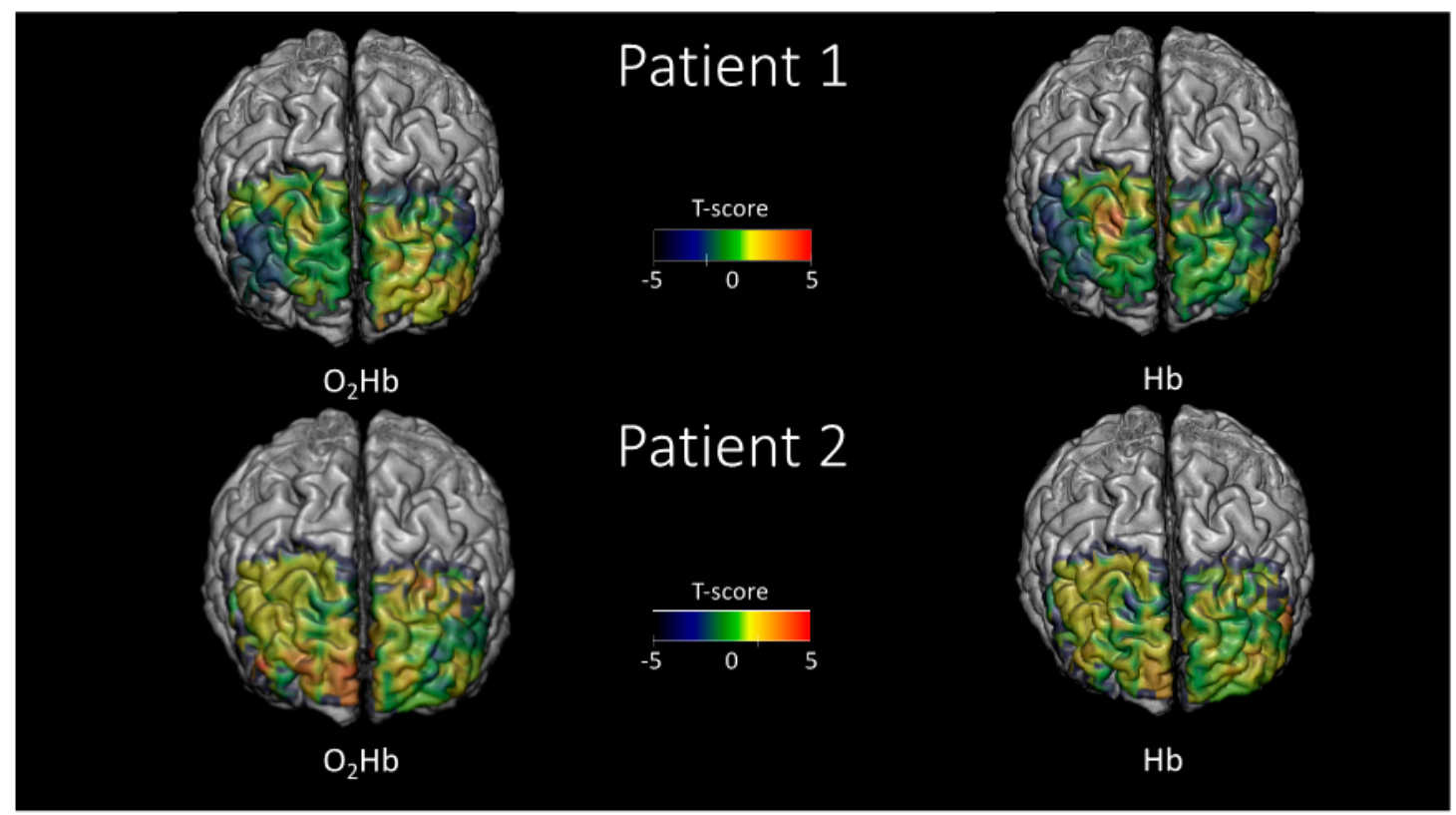

Figure 6. Statistical parametric maps (t-scores) evaluated employing the functional near-infrared spectroscopy-diffuse optical tomography (fNIRS-DOT) analysis and comparing the variability of the signal between task and rest for the Digit Span (DS) backward test. The maps are reported in regions where the spatial sensitivity of the optical array was sufficient (up to an attenuation of the average optical sensitivity of 1000 times).

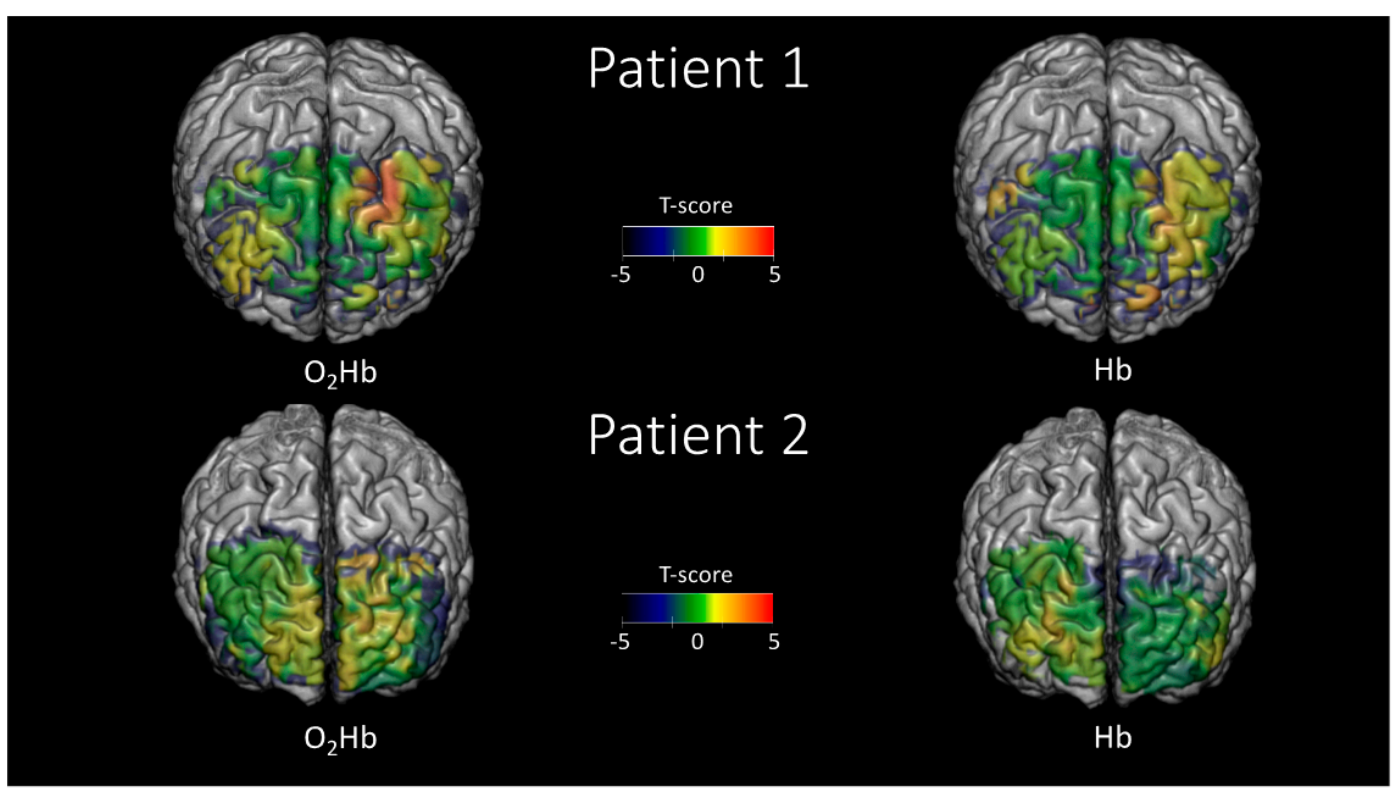

Figure 7. Statistical parametric maps (t-scores) evaluated employing the functional near-infrared spectroscopy-diffuse optical tomography (fNIRS-DOT) analysis and comparing the variability of the signal between task and rest for the Symbol Search (SS) test. The maps are reported in regions where the spatial sensitivity of the optical array was sufficient (up to an attenuation of the average optical sensitivity of 1000 times).

Figure 5 reports the statistical parametric maps (t-scores), obtained using the GLM approach, during the SWG. In both patients, a clear spatial anticorrelation in the maps of $\mathrm{O}_{2} \mathrm{Hb}$ and $\mathrm{HHb}$ is visible. The anticorrelation of $\mathrm{O}_{2} \mathrm{Hb}$ and $\mathrm{HHb}$ is highly indicative of the sensitivity to hemodynamic brain activity, which is the only physiological event that induces opposite oscillations of the two hemoglobin forms. It should be noticed that those $t$-scores above $t=1.65$ or below $t=-1.65$ suggest a 
brain activation, as the null hypothesis probability (activation not significantly different from 0 ) within these values can be considered equal to the one with $p<0.05$ in an uncorrected scenario.

Figure 6 reports the statistical parametric maps (t-scores), evaluated using the hemoglobin variability comparison between task and rest approach, during the DS backward test. In this case, $\mathrm{O}_{2} \mathrm{Hb}$ and $\mathrm{HHb}$ showed correlated maps, rather than anticorrelated ones as reported in Figure 5. This result is intrinsic to the nature of the analysis performed that evaluates only the statistical amplitude of the oscillations associated with brain activity, and not their sign.

Figure 7 reports the statistical parametric maps (t-scores), evaluated using the hemoglobin variability comparison between task and rest approach, during the SS test. In this case, for the same reason as described for Figure 6, $\mathrm{O}_{2} \mathrm{Hb}$ and $\mathrm{HHb}$ showed correlated maps.

\section{Discussion}

3.1. Tomographic Task-Related Functional Near-Infrared Spectroscopy Assessment in Sport-Related Concussion within 72 Hours from Injury

These results show a proof of concept of application of task-related fNIRS-DOT in acute SRC patients while performing the SWG, DS backward, and SS tasks, during their clinical assessment.

No changes were made to the neurocognitive tasks as presented in clinical practice. This is in agreement with other optical studies on patients (e.g., SRC, Alzheimer's disease), which aimed to scan the brain activation patterns elicited during the clinical assessment (e.g., ImPACT) [37,47].

The 3 neurocognitive tasks used in this study had different modalities of execution: fixation on a screen in the SWG, repetition of numbers in the DS backward, and a pencil-paper task in the SS. This highlights the versatility of the optical recordings to different modalities of neurocognitive tasks. Different impairments related to SRC have been reported, which consequently demands the use of a battery of tests to scan SRC patients effectively, as a single test would not be sufficient to test the entire spectrum of possible dysfunctions $[15,48]$. The versatility of fNIRS-DOT to accommodate different modalities of execution of neurocognitive tests makes this neuroimaging technique particularly suitable for the clinical assessment of SRC patients. It should be noted that the execution of the SS or DS backward during fMRI scanning requires adaptation of the modalities of testing to suit the scanner or limitation to covert task responses [49,50]. It should also be highlighted that the SWG, unlike the other 2 tests, does not permit collection of behavior results. Limiting the analysis to the brain activation pattern alone can carry a bias in the analysis of the brain activation mapping, as this itself would be incorrectly assumed to be proof of the cognitive engagement, rather than seeking this proof in the behavior result [51].

The brain activation pattern had to be measured from the brain hemodynamic response using two statistical single-subject models: GLM and comparison in the variability of the signals between task and baseline for $\mathrm{O}_{2} \mathrm{Hb}$ and $\mathrm{HHb}$. To extend the GLM to the optical data collected during DS backward and SS, the patterns of these tests must be edited into multiple blocks, similar to the template of the SWG. It should be noted that previous tomographic optical analysis on SRC patients used the GLM to map brain activation [37].

The optical analysis reported herein was recorded within $72 \mathrm{~h}$ of the patients' injuries. The complex pathogenesis of concussion (e.g., energy crisis, altered neurotransmission) is reflected by different grades of severity of brain status according to the time of analysis since injury [52]. Behavior results in the neurocognitive tasks in SRC athletes can change with a progressive normalization of the parameters [53]. Therefore, optical analysis of the cortical activations related to these tests should be aimed at scanning patients within a short timeframe from injury so that early abnormalities can be detected. This would make a proper assessment of the severity of injury possible, and clinical decisions could be taken accordingly. Furthermore, the detection of early abnormalities can be useful to track their evolution during the patients' recovery, and manage the follow-up accordingly. 


\subsection{Brain Activation Patterns Measured}

\subsubsection{Silent Word Generation}

The fNIRS-DOT results presented in this study showed stronger activation (positive t-scores for $\mathrm{O}_{2} \mathrm{Hb}$ coupled with negative $\mathrm{HHb}$ t-score) in the scanned areas of the prefrontal cortex in the left hemisphere (LH) than in the right hemisphere (RH). This is in agreement with the known brain language areas and fMRI results with SWG.

The language functions are mainly present in the LH [54,55]. The brain pattern is mainly compounded by two pathways: the dorsal pathway, which connects the Wernicke area, in the superior temporal gyrus, to the motor homunculus, in the anterior frontal gyrus; and the ventral pathway, which connects the Broca area, in the ventrolateral prefrontal cortex, to the middle and inferior temporal gyrus [56]. As expected by the activation pattern mentioned above, fMRI studies showed that the SWG is associated with brain activation of the prefrontal cortex, and stronger activation in the LH than in the RH [57-59].

\subsubsection{Digit Span}

The fNIRS-DOT results showed higher variability in $\mathrm{O}_{2} \mathrm{Hb}$ levels during the DS backward test than the baseline in areas of the prefrontal cortex, which can be considered a sign of brain activation due to the task.

These results are in agreement with previous NIRS studies which showed an increase in levels of $\mathrm{O}_{2} \mathrm{Hb}$ in the prefrontal cortex of both hemispheres during the DS backward and with studies using fMRI, transcranial magnetic stimulation, and positive emission tomography which suggested a crucial role of activation in the prefrontal cortex to perform the DS backward [50,60-63].

\subsubsection{Symbol Search}

Similar to the DS backward results explained in Section 3.2.2, the fNIRS-DOT results showed an increased variance in $\mathrm{O}_{2} \mathrm{Hb}$ levels between the task and the baseline, which can be related to the neurocognitive activation triggered by the task.

To the best of our knowledge, this is the first example of tomographic reconstruction of brain activation related to SS as performed in clinical practice.

\subsection{Design of Clinical Studies for Tomographic Functional Near-Infrared Spectroscopy in Sport-Related Concussion}

Analysis of the behavior results from neurocognitive tests solely is currently insufficient for use for SRC clinical assessment [64-66]. Clinical studies on SRC patients could combine the brain activation patterns with the behavior results from the neurocognitive tests. This could give a better insight into the patents' statuses and help clinicians to make decisions accordingly.

The results from this study can pave the way for further clinical studies which aim to investigate abnormalities in the brain activation after SRC using task-related fNIRS-DOT, similar to previous task-related fMRI studies. The results herein presented can aid the design of the most suitable data collection (e.g., neurocognitive test) and analysis (e.g., statistical model) techniques for these future research studies.

It should also be mentioned that tomographic optical imaging (DOT) of the whole head can be used to map resting-state cortical activation, in a similar way to experiments done with resting-state fMRI in SRC [31,67].

\subsection{Limitations}

Several limitations should be mentioned about the study itself and the clinical application of task-related fNIRS-DOT in SRC. 


\subsubsection{Sample Size}

The small sample size limited the analysis to single-subject statistical models, without extending to multiple-subject analysis [68]. Therefore, the capacity to retrieve the brain activation pattern across SRC athletes and to compare it between physiological and pathological states was not tested. Furthermore, the small sample size and the limitation to single-subject statistical analysis means that similarities in the brain activation patterns between subjects should be interpreted with caution.

\subsubsection{Confinement of the Results to the Illuminated Areas}

The prefrontal cortex may not have been completely covered in the SD layout used. Due to the co-registration of the optical signal into an MRI template rather than a subject-specific structural MRI, the extension of the illuminated brain area in each patient could not be measured to a high accuracy. Therefore, conclusions on the prefrontal cortex activation are subject to the areas scanned.

\subsubsection{Limitations of the Statistical Model of the Variance of Levels of Oxyhemoglobin}

Compared to the GLM, the analysis of variability of oscillations in $\mathrm{O}_{2} \mathrm{Hb}$ and $\mathrm{HHb}$ yields the disadvantage that the values obtained are agnostic to an increase or decrease of hemoglobin. Furthermore, task-related changes in the spontaneous hemodynamic oscillations may influence, completely or partially, the results obtained [27]. Consequently, the map plotted may not be related to the cortical activation only.

\subsubsection{Extracranial Tissue Interference}

Although the DOT approach intrinsically dampens the interference from the extracranial tissue (ECT), due to the positions of the probes on the scalp, hemodynamic interference may have partially affected the signal detected [69]. Moreover, the interference with the cerebral signal by the ECT hemodynamic may not be homogenous across the forehead [70].

The map of cortical activation during neurocognitive tests which require movement responses, such as the SS, may be less accurate than analysis during a task where participants stay still, such as the SWG, because movement artifacts and systemic motion-generated responses in the ECT could be additional confounding factors [27].

\subsubsection{Hemodynamic Impairments in Sport-Related Concussion}

The task-related fNIRS-DOT analysis proposed in this study measures changes in the levels of $\mathrm{O}_{2} \mathrm{Hb}$ and $\mathrm{HHb}$ during the acquisition time, without assessing their baseline levels. Therefore, as proposed by Forcione et al., different levels of cerebral blood flow across the brain in SRC could influence the brain activation reported [24].

Furthermore, the lack of a gradual increase in difficulty of the neurocognitive tasks, as in the SWG or SS, and/or the inability to account for such an increase in the optical data analysis, as in the DS backward, exposes the brain activation pattern detected by fNIRS-DOT to confoundment by a pathological, non-linear, systemic hemodynamic response in SRC patients [24]. Future studies may address this problem by adding heart rate and/or blood pressure monitoring to the data acquisition method described herein.

\subsubsection{Multiple Patterns of Brain Activation}

There could be different brain activation patterns across individuals with different lifestyles. As a matter of fact, there are multiple variables, such as physical activity, education, type of sport practiced, which can affect the behavior results of neurocognitive tests and the cortical activation detected [71-73]. Therefore, non-standard brain activation would not necessarily link to impairments due to SRC but could instead be the result of comparisons between different group populations. Clinical studies should define markers in the brain activation pattern, which can be linked to dysfunctions related 
to SRC, by comparing brain activation patterns after SRC with the subject baseline values or with normative values from a non-concussed population, similar to the existing analysis in neurocognitive tests used in SRC [74].

\section{Materials and Methods}

\subsection{Patients}

Two SRC rugby athletes (1 male, 35 and 23 years old) who were referred to the Birmingham concussion clinic at the Queen Elizabeth Hospital Birmingham or University of Birmingham (UK), right-handed, native English speakers, playing at amateur and professional levels, were scanned within $72 \mathrm{~h}$ from injury as part of the RECOS study (REpetitive COncussion in Sport) (IRAS ID: 216703; Ref. REC: 17/EE/0275) [75].

Patients took part in this study after providing informed written consent. The study conforms to the Declaration of Helsinki and it was approved by the East of England-Essex Research Ethics Committee on 22 September 2017.

\subsection{Data Recording}

\subsubsection{Optical Helmet}

A custom-built optical helmet, as described by Tan et al., was used to position the optical probes on patients' heads [76]. A custom-made MATLAB graphic user interface, NOMAD, Near-Infrared Optode Montage Automated Design (https://github.com/kylemath/nomad), developed by Mathewson et al., was used to evaluate the optimal SD locations on the helmet, in order to illuminate the prefrontal cortex of both hemispheres and avoid cross-talk between SD pairs in a time-multiplexing cycle of light-emission [77]. The prefrontal cortex was preferred over other areas because it was deemed to be activated by the neurocognitive tests used and due to the absence of hair on the forehead, which can impede the detection of optical signals.

\subsubsection{Digitization}

A "3-space" FastTrak 3-D digitizer (Polhemus, Colchester, VT, USA) was used for digitizing the positions of the probes on the helmet and of three fiducial points (i.e., nasion, left and right pre-auricula). The positions of the pre-auriculae were defined using a T-bar, as described by Whalen et al. [78].

\subsubsection{Optical Device}

15 detectors and 16 dual-wavelength sources of a frequency-domain near-infrared spectroscopy device (Imagent; ISS Inc., Champaign, IL, USA) were used to collect optical data. The location of one of the sources could not be resolved in the time-multiplexing cycle described in Section 4.2.1 and so it was not positioned on patients' scalps. Each source emitted light at $830 \mathrm{~nm}$ and $690 \mathrm{~nm}$ wavelength, and they were modulated at $140 \mathrm{MHz}$. Optical data, accounting for a complete time-multiplexing cycle of all the sources, were sampled at $39.7365 \mathrm{~Hz}$.

\subsubsection{Testing Set-Up}

Patients were scanned while sat in a chair. A "double halo", based on the description from Wheelock et al., was used to support the fibers [31]. Small plastic cones were affixed to the helmet's holes, next to the probes, to secure them to the helmet and maintain good scalp-optode coupling during the recording. To maximize the scalp-optode coupling, care was taken to move the hair from the helmet's holes before positioning the probes.

An examiner sat close to the patients to interact with them if requested by the task (e.g., DS backward), and to control the correct execution of the tasks. A computer screen was placed in front of 
the patients (Figure $8 \mathrm{~A}$ ), and, during the SS, a small table was positioned in between to perform the task (Figure 8B).
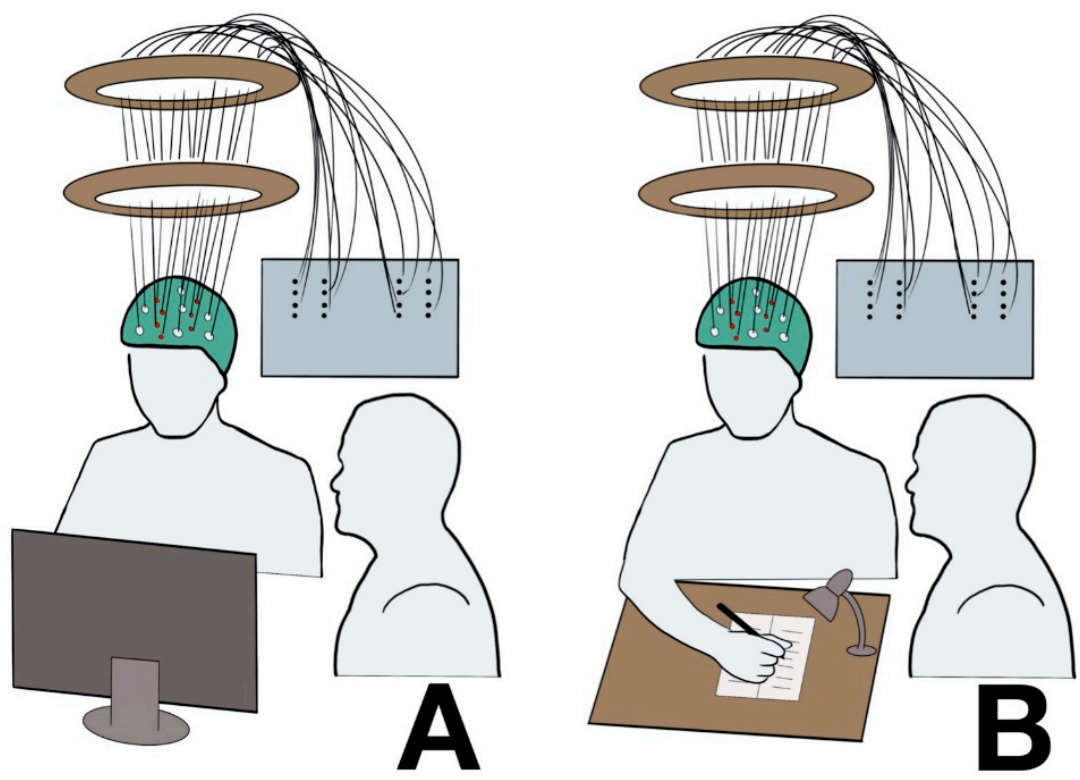

Figure 8. Representation of the test set-up. (A): Silent Word Generation (SWG), and Digit Span (DS) backward. (B): Symbol Search (SS).

The light in the room was dimmed to reduce contamination by ambient light. During the SS, a small portable lamp was used to illuminate the table (Figure 8B).

\subsubsection{Data Acquisition Protocol}

Patients had to perform 3 neurocognitive tests commonly used in clinical practice: SWG, DS backward, and SS (Figure 9).

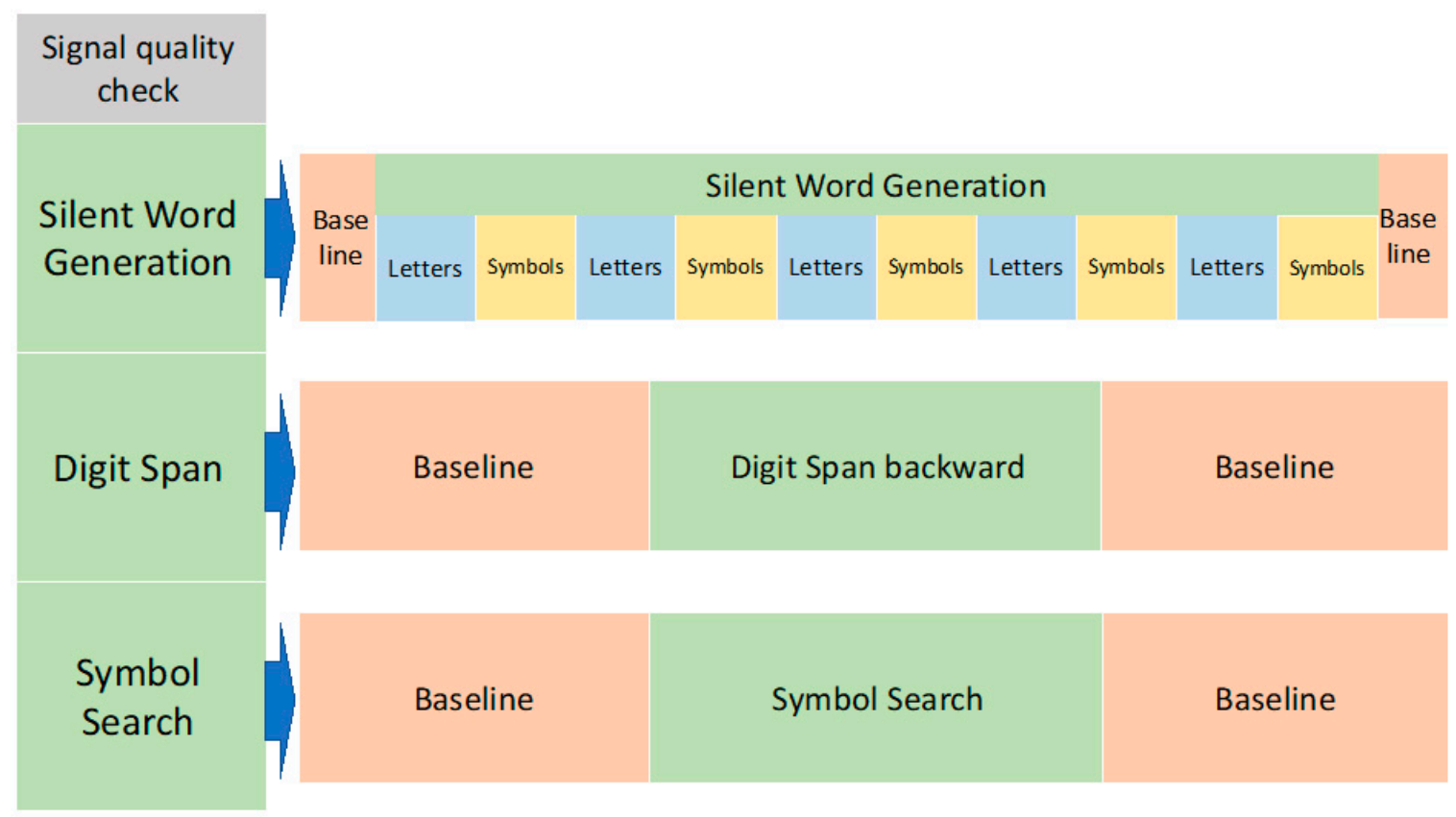

Figure 9. Experimental protocol. 
In order to investigate the feasibility of tomographic optical recordings during the tasks applied in clinical practice, no changes were made to the templates of the tests. Before the start of the recording, the tasks were explained, and patients had time to familiarize themselves with the tasks.

The optical data recordings were preceded by a signal quality check, and adjustments to the scalp-optode coupling were made as deemed necessary.

Each task was preceded and followed by 1 min of resting-state, during which patients had to stare at a cross projected on the screen. Two resting-state minutes in-between tasks were considered sufficient to allow hemoglobin levels to plateau and eliminate overlapping signals between tasks [79]. The $1 \mathrm{~min}$ of resting-state before the task was used as baseline in the statistical analysis of the variability of $\mathrm{O}_{2} \mathrm{Hb}$ and $\mathrm{HHb}$, as explained in Section 4.3.

An examiner manually time-marked the different phases of the protocol.

The duration of the protocol was approximately $30 \mathrm{~min}$.

\section{Silent Word Generation}

The SWG is a common task used in clinical practice to assess the language areas before brain surgery [57].

The task was divided into 5 blocks. In each block, 3 slides showing a letter and 3 slides showing a nonsense symbol were projected on a screen each for $10 \mathrm{~s}$, for a total block time of $60 \mathrm{~s}$. The patients were instructed to think of as many English words as possible that began with the letter shown and to rest when the nonsense symbols were shown.

\section{Digit Span Backward}

The DS is part of the Wechsler Adult Intelligence Scales, Fourth Edition (WAIS-IV) test. The WAIS-IV has been used to evaluate different intellectual skills in TBI patients [80]. In particular, the DS backward is indicative of working memory and concentration skills [15].

The DS is compounded by a forward and backward version. In this study, only the backward version was carried out. The DS backward involved repeating a sequence of numbers in the reverse order to that in which they were announced. An examiner called a pair of sequences of 3 numbers each and, if the patient repeated them correctly, progressively longer sequences were given. When there was a mistake in both sequences, the task ended.

\section{Symbol Search}

Like the DS, the SS is part of the WAIS-IV, and it has been reported to be one of the most sensitive neurocognitive tests to TBI related impairments [80]. The SS is targeted at assessing visuospatial attention and cognitive processing speed [49].

Participants were presented with multiple lines of nonsense symbols. Each line comprised 2 sets of symbols, of length 2 and 5. Participants had to determine if a symbol appeared in both sets. If so, participants were instructed to strike through the repeated symbol, and if not, to strike through a "NO" box. Participants were instructed to complete as many lines as they could, to the highest possible accuracy, within $2 \mathrm{~min}$.

\subsection{Data Analysis}

Digitized optode's locations were co-registered to a structural MRI template using a 3 fiducial-alignment approach [81]. The direct current (DC) intensity data (i.e., average measures of the amount of light produced by a specific source and reaching a particular detector during a multiplexed $1.6 \mathrm{~ms}$ interval) were normalized (by dividing them by their mean value) and converted into optical density (OD). Furthermore, the ODs were movement-corrected, and band-pass filtered between $0.01 \mathrm{~Hz}$ and $0.3 \mathrm{~Hz}$ (zero-lag, 4th order, Butterworth digital filter) [82]. For inspection of signal quality, a channel-based hemoglobin conversion was implemented employing the modified 
Beer-Lambert Law, with assumed hemoglobin extinction coefficients and tissue differential pathlength factors at the wavelengths of interest [83-86].

To generate a 3D reconstruction of changes in optical properties and hemoglobin oscillations in the frontal region investigated, a model of light propagation within the head (forward model) and an inverse procedure were implemented. The finite-element method (FEM) applied to the diffusion equation was used to estimate the forward model. The FEM software NIRFAST was used to model light propagation through the head and to compute the Jacobian (sensitivity) matrices of DC light intensity to absorption changes induced by hemoglobin oscillations in each SD couple $[87,88]$. "Fine" meshes (maximum tetrahedral volume $2 \mathrm{~mm}^{3}$ ) were generated for FEM using the MATLAB software iso2mesh [89]. The heterogeneous head models were based on the segmentation of the MRI template. Segmentation of the skull and scalp, cerebrospinal fluid, white matter, and gray matter was performed using statistical parametric mapping functions [44]. Baseline optical properties (absorption coefficient $[\mu \mathrm{a}]$, reduced scattering coefficient $\left[\mu \mathrm{s}^{\prime}\right]$ and refraction index $\left.[\eta]\right)$ of the tissues at the relevant wavelengths were taken from Tian et al. [90]. An inverse procedure based on energy minimization of the solution was used to convert intensity changes on individual channels to absorption changes in voxel space at each wavelength [88]. The modified Beer-Lambert law was inverted to evaluate $\mathrm{O}_{2} \mathrm{Hb}$ and $\mathrm{HHb}$ oscillations given absorption modulation at the 2 wavelengths employed. The extinction coefficients of the 2 forms of hemoglobin at the $690 \mathrm{~nm}$ and $830 \mathrm{~nm}$ wavelengths were extracted from Zijlstra et al. in similarity with the channel-based analysis [84].

Once tomographic reconstruction of $\mathrm{O}_{2} \mathrm{Hb}$ and $\mathrm{HHb}$ oscillations was obtained, 2 different statistical approaches were employed to evaluate brain activity. In particular, for the SWG test, the defined structure of the task permitted use of a GLM analysis [44]. In the GLM analysis, the nonsense symbol was considered as baseline, whereas the letters were considered as stimulation.

On the contrary, for the DS backward and SS, due to the absence of a defined pattern of stimulation, an ad-hoc analysis was implemented. In particular, an evaluation of the change in variability in $\mathrm{O}_{2} \mathrm{Hb}$ and $\mathrm{HHb}$ oscillations associated with brain activity was implemented by employing $10 \mathrm{~s}$ integration windows. The windows were non-overlapping, and they were evaluated in the $1 \mathrm{~min}$ of resting-state prior to beginning the task to estimate the baseline level and during the stimulation to estimate the task-induced brain hemodynamic modulation [91].

\section{Conclusions}

In conclusion, this study shows an application of task-related fNIRS-DOT in the analysis of brain activation in SRC patients within $72 \mathrm{~h}$ from injury. This study highlights the advantages and limitations of the use of this tomographic optical technique in the assessment of acute SRC patients. Future studies should aim to resolve or reduce the limitations met, identify biomarkers related to acute SRC in the optical assessment, and test the relevance of these biomarkers in the clinical decision process of return-to-play in SRC athletes.

Author Contributions: Conceptualization, M.F.; methodology, M.F., A.M.C., D.P.; software, A.M.C., D.P.; formal analysis, M.F., A.M.C., D.P.; investigation, M.F.; resources, M.F.; data curation, M.F.; writing—original draft preparation, M.F., A.M.C., D.P.; writing—review and editing, D.H., D.J.D., P.O.; supervision, A.M., A.B. All authors have read and agreed to the published version of the manuscript.

Funding: This article was funded by the project "Brain Injury and Trauma Monitoring Using Advanced Photonics", financed by the European Union Horizon 2020 Research and Innovation Program, under grant agreement 675332, through the National Institute for Health Research Surgical Reconstruction and Microbiology Research Centre (NIHR SRMRC), partnership between University Hospitals Birmingham NHS Foundation Trust, the University of Birmingham, and the Royal Centre for Defence Medicine. The views expressed are those of the authors and not necessarily those of the NHS, the NIHR or the Department of Health.

Acknowledgments: The authors are thankful to the patients enrolled and to the health care providers of the Birmingham concussion clinic.

Conflicts of Interest: The authors declare no conflict of interest. 


\section{Abbreviations}

$\begin{array}{ll}\text { SRC } & \text { Sport-related concussion } \\ \text { TBI } & \text { Traumatic brain injury } \\ \text { MRI } & \text { Magnetic resonance imaging } \\ \text { ImPACT } & \text { Immediate Post-Concussion Assessment and Cognitive Testing } \\ \text { SCAT } & \text { Sport Concussion Assessment Tool } \\ \text { fMRI } & \text { Functional magnetic resonance imaging } \\ \text { fNIRS } & \text { Functional near-infrared spectroscopy } \\ \mathrm{O}_{2} \mathrm{Hb} & \text { Oxyhemoglobin } \\ \text { HHb } & \text { Deoxyhemoglobin } \\ \text { DOT } & \text { Diffuse optical tomography } \\ \text { SWG } & \text { Silent Word Generation } \\ \text { DS } & \text { Digit Span } \\ \text { SS } & \text { Symbol Search } \\ \text { SD } & \text { Source-detector } \\ \mu M & \text { Micromolar } \\ \text { GLM } & \text { General Linear Model } \\ \text { LH } & \text { Left hemisphere } \\ \text { RH } & \text { Right hemisphere } \\ \text { ECT } & \text { Extracranial tissue } \\ \text { WAIS-IV } & \text { Wechsler Adult Intelligence Scales, Fourth Edition } \\ \text { DC } & \text { Direct current } \\ \text { OD } & \text { Optical density } \\ \text { FEM } & \text { Finite-element method } \\ & \end{array}$

\section{References}

1. McCrory, P.; Meeuwisse, W.; Dvorak, J.; Aubry, M.; Bailes, J.; Broglio, S.; Cantu, R.C.; Cassidy, D.; Echemendia, R.J.; Castellani, R.J.; et al. Consensus statement on concussion in sport-the 5(th) international conference on concussion in sport held in Berlin, October 2016. Br. J. Sports Med. 2017, 51, 838-847. [CrossRef] [PubMed]

2. McCrory, P.; Meeuwisse, W.H.; Echemendia, R.J.; Iverson, G.L.; Dvorak, J.; Kutcher, J.S. What is the lowest threshold to make a diagnosis of concussion? Br. J. Sports Med. 2013, 47, 268-271. [CrossRef] [PubMed]

3. Langlois, J.A.; Rutland-Brown, W.; Wald, M.M. The epidemiology and impact of traumatic brain injury: A brief overview. J. Head Trauma Rehabil. 2006, 21, 375-378. [CrossRef]

4. Zuckerman, S.L.; Kerr, Z.Y; Yengo-Kahn, A.; Wasserman, E.; Covassin, T.; Solomon, G.S. Epidemiology of Sports-Related Concussion in NCAA Athletes From 2009-2010 to 2013-2014: Incidence, Recurrence, and Mechanisms. Am. J. Sports Med. 2015, 43, 2654-2662. [CrossRef] [PubMed]

5. McCrea, M.; Hammeke, T.; Olsen, G.; Leo, P.; Guskiewicz, K. Unreported concussion in high school football players: Implications for prevention. Clin. J. Sport Med. 2004, 14, 13-17. [CrossRef]

6. Lovell, M.R.; Collins, M.W.; Maroon, J.C.; Cantu, R.; Hawn, M.A.; Burke, C.J.; Fu, F. INACCURACY OF SYMPTOM REPORTING FOLLOWING CONCUSSION IN ATHLETES. Med. Sci. Sports Exerc. 2002, 34, S298. [CrossRef]

7. Vagnozzi, R.; Tavazzi, B.; Signoretti, S.; Amorini, A.M.; Belli, A.; Cimatti, M.; Delfini, R.; Di Pietro, V.; Finocchiaro, A.; Lazzarino, G. Temporal window of metabolic brain vulnerability to concussions: Mitochondrial-related impairment-part I. Neurosurgery 2007, 61, 379-388, discussion 388-389. [CrossRef]

8. Tavazzi, B.; Vagnozzi, R.; Signoretti, S.; Amorini, A.M.; Belli, A.; Cimatti, M.; Delfini, R.; Di Pietro, V.; Finocchiaro, A.; Lazzarino, G. Temporal window of metabolic brain vulnerability to concussions: Oxidative and nitrosative stresses-part II. Neurosurgery 2007, 61, 390-395, discussion 395-396. [CrossRef]

9. Longhi, L.; Saatman, K.E.; Fujimoto, S.; Raghupathi, R.; Meaney, D.F.; Davis, J.; McMillan, B.S.A.; Conte, V.; Laurer, H.L.; Stein, S.; et al. Temporal window of vulnerability to repetitive experimental concussive brain injury. Neurosurgery 2005, 56, 364-374, discussion 364-374. [CrossRef] 
10. Guskiewicz, K.M.; McCrea, M.; Marshall, S.W.; Cantu, R.C.; Randolph, C.; Barr, W.; Onate, J.A.; Kelly, J.P. Cumulative effects associated with recurrent concussion in collegiate football players: The NCAA Concussion Study. JAMA 2003, 290, 2549-2555. [CrossRef]

11. Cross, M.; Kemp, S.; Smith, A.; Trewartha, G.; Stokes, K. Professional Rugby Union players have a $60 \%$ greater risk of time loss injury after concussion: A 2-season prospective study of clinical outcomes. Br. J. Sports Med. 2016, 50, 926-931. [CrossRef] [PubMed]

12. Nordstrom, A.; Nordstrom, P.; Ekstrand, J. Sports-related concussion increases the risk of subsequent injury by about 50\% in elite male football players. Br. J. Sports Med. 2014, 48, 1447-1450. [CrossRef] [PubMed]

13. McCrea, M.; Guskiewicz, K.; Randolph, C.; Barr, W.B.; Hammeke, T.A.; Marshall, S.W.; Kelly, J.P. Effects of a symptom-free waiting period on clinical outcome and risk of reinjury after sport-related concussion. Neurosurgery 2009, 65, 876-882, discussion 882-883. [CrossRef] [PubMed]

14. Echemendia, R.J.; Giza, C.C.; Kutcher, J.S. Developing guidelines for return to play: Consensus and evidence-based approaches. Brain Inj. 2015, 29, 185-194. [CrossRef] [PubMed]

15. Echemendia, R.J.; Putukian, M.; Mackin, R.S.; Julian, L.; Shoss, N. Neuropsychological test performance prior to and following sports-related mild traumatic brain injury. Clin. J. Sport Med. 2001, 11, 23-31. [CrossRef]

16. Lovell, M.R.; Collins, M.W.; Iverson, G.L.; Field, M.; Maroon, J.C.; Cantu, R.; Podell, K.; Powell, J.W.; Belza, M.; Fu, F.H. Recovery from mild concussion in high school athletes. J. Neurosurg. 2003, 98, 296-301. [CrossRef]

17. Broglio, S.P.; Macciocchi, S.N.; Ferrara, M.S. Neurocognitive performance of concussed athletes when symptom free. J. Athl. Train. 2007, 42, 504-508.

18. Van Kampen, D.A.; Lovell, M.R.; Pardini, J.E.; Collins, M.W.; Fu, F.H. The "value added" of neurocognitive testing after sports-related concussion. Am. J. Sports Med. 2006, 34, 1630-1635. [CrossRef]

19. Slobounov, S.; Tutwiler, R.; Sebastianelli, W.; Slobounov, E. Alteration of postural responses to visual field motion in mild traumatic brain injury. Neurosurgery 2006, 59, 134-139, discussion 134-139. [CrossRef]

20. Slobounov, S.; Slobounov, E.; Sebastianelli, W.; Cao, C.; Newell, K. Differential rate of recovery in athletes after first and second concussion episodes. Neurosurgery 2007, 61, 338-344, discussion 344. [CrossRef]

21. Vagnozzi, R.; Signoretti, S.; Cristofori, L.; Alessandrini, F.; Floris, R.; Isgro, E.; Ria, A.; Marziali, S.; Zoccatelli, G.; Tavazzi, B.; et al. Assessment of metabolic brain damage and recovery following mild traumatic brain injury: A multicentre, proton magnetic resonance spectroscopic study in concussed patients. Brain 2010, 133, 3232-3242. [CrossRef] [PubMed]

22. Lumba-Brown, A.; Ghajar, J.; Cornwell, J.; Bloom, O.J.; Chesnutt, J.; Clugston, J.R.; Kolluri, R.; Leddy, J.J.; Teramoto, M.; Gioia, G. Representation of concussion subtypes in common postconcussion symptom-rating scales. Concussion 2019, 4, CNC65. [CrossRef] [PubMed]

23. Echemendia, R.J.; Broglio, S.P.; Davis, G.A.; Guskiewicz, K.M.; Hayden, K.A.; Leddy, J.J.; Meehan, W.P., III; Putukian, M.; Sullivan, S.J.; Schneider, K.J.; et al. What tests and measures should be added to the SCAT3 and related tests to improve their reliability, sensitivity and/or specificity in sideline concussion diagnosis? A systematic review. Br. J. Sports Med. 2017, 51, 895-901. [CrossRef] [PubMed]

24. Forcione, M.; Colonnese, C.; Belli, A. Cerebral Hemodynamic Influences in Task-Related Functional Magnetic Resonance Imaging and Near-Infrared Spectroscopy in Acute Sport-Related Concussion: A Review. J. Imaging 2018, 4, 59. [CrossRef]

25. Eklund, A.; Nichols, T.E.; Knutsson, H. Cluster failure: Why fMRI inferences for spatial extent have inflated false-positive rates. Proc. Natl. Acad. Sci. USA 2016, 113, 7900-7905. [CrossRef] [PubMed]

26. Iyengar, S. Case for fMRI data repositories. Proc. Natl. Acad. Sci. USA 2016, 113, 7699-7700. [CrossRef]

27. Scholkmann, F.; Kleiser, S.; Metz, A.J.; Zimmermann, R.; Mata Pavia, J.; Wolf, U.; Wolf, M. A review on continuous wave functional near-infrared spectroscopy and imaging instrumentation and methodology. Neuroimage 2014, 85 Pt 1, 6-27. [CrossRef]

28. Croce, P.; Zappasodi, F.; Merla, A.; Chiarelli, A.M. Exploiting neurovascular coupling: A Bayesian sequential Monte Carlo approach applied to simulated EEG fNIRS data. J. Neural Eng. 2017, 14, 046029. [CrossRef]

29. Boas, D.A.; Brooks, D.H.; Miller, E.L.; DiMarzio, C.A.; Kilmer, M.; Gaudette, R.J.; Quan, Z. Imaging the body with diffuse optical tomography. IEEE Signal Process. Mag. 2001, 18, 57-75. [CrossRef]

30. Chiarelli, A.M.; Maclin, E.L.; Low, K.A.; Mathewson, K.E.; Fabiani, M.; Gratton, G. Combining energy and Laplacian regularization to accurately retrieve the depth of brain activity of diffuse optical tomographic data. J. Biomed. Opt. 2016, 21, 36008. [CrossRef] 
31. Wheelock, M.D.; Culver, J.P.; Eggebrecht, A.T. High-density diffuse optical tomography for imaging human brain function. Rev. Sci. Instrum. 2019, 90, 051101. [CrossRef] [PubMed]

32. Cui, X.; Bray, S.; Bryant, D.M.; Glover, G.H.; Reiss, A.L. A quantitative comparison of NIRS and fMRI across multiple cognitive tasks. Neuroimage 2011, 54, 2808-2821. [CrossRef] [PubMed]

33. Amyot, F.; Zimmermann, T.; Riley, J.; Kainerstorfer, J.M.; Chernomordik, V.; Mooshagian, E.; Najafizadeh, L.; Krueger, F.; Gandjbakhche, A.H.; Wassermann, E.M. Normative database of judgment of complexity task with functional near infrared spectroscopy-application for TBI. Neuroimage 2012, 60, 879-883. [CrossRef] [PubMed]

34. Ferradal, S.L.; Eggebrecht, A.T.; Hassanpour, M.; Snyder, A.Z.; Culver, J.P. Atlas-based head modeling and spatial normalization for high-density diffuse optical tomography: In vivo validation against fMRI. Neuroimage 2014, 85 Pt 1, 117-126. [CrossRef]

35. Eggebrecht, A.T.; White, B.R.; Ferradal, S.L.; Chen, C.; Zhan, Y.; Snyder, A.Z.; Dehghani, H.; Culver, J.P. A quantitative spatial comparison of high-density diffuse optical tomography and fMRI cortical mapping. Neuroimage 2012, 61, 1120-1128. [CrossRef]

36. Sharma, A.; Hind, K.; Hume, P.; Singh, J.; Neary, J.P. Neurovascular Coupling by Functional Near Infra-Red Spectroscopy and Sport-Related Concussion in Retired Rugby Players: The UK Rugby Health Project. Front. Hum. Neurosci. 2020, 14, 42. [CrossRef]

37. Kontos, A.P.; Huppert, T.J.; Beluk, N.H.; Elbin, R.J.; Henry, L.C.; French, J.; Dakan, S.M.; Collins, M.W. Brain activation during neurocognitive testing using functional near-infrared spectroscopy in patients following concussion compared to healthy controls. Brain Imaging Behav. 2014, 8, 621-634. [CrossRef]

38. Urban, K.J.; Barlow, K.M.; Jimenez, J.J.; Goodyear, B.G.; Dunn, J.F. Functional near-infrared spectroscopy reveals reduced interhemispheric cortical communication after pediatric concussion. J. Neurotrauma 2015, 32, 833-840. [CrossRef]

39. Helmich, I.; Berger, A.; Lausberg, H. Neural Control of Posture in Individuals with Persisting Postconcussion Symptoms. Med. Sci. Sports Exerc. 2016, 48, 2362-2369. [CrossRef]

40. Helmich, I.; Saluja, R.S.; Lausberg, H.; Kempe, M.; Furley, P.; Berger, A.; Chen, J.K.; Ptito, A. Persistent Postconcussive Symptoms Are Accompanied by Decreased Functional Brain Oxygenation. J. Neuropsychiatry Clin. Neurosci. 2015, 27, 287-298. [CrossRef]

41. Helmich, I.; Coenen, J.; Henckert, S.; Pardalis, E.; Schupp, S.; Lausberg, H. Reduced frontopolar brain activation characterizes concussed athletes with balance deficits. Neuroimage Clin. 2020, 25, 102164. [CrossRef] [PubMed]

42. Hocke, L.M.; Duszynski, C.C.; Debert, C.T.; Dleikan, D.; Dunn, J.F. Reduced Functional Connectivity in Adults with Persistent Post-Concussion Symptoms: A Functional Near-Infrared Spectroscopy Study. J. Neurotrauma 2018, 35, 1224-1232. [CrossRef] [PubMed]

43. Bishop, S.A.; Neary, J.P. Assessing prefrontal cortex oxygenation after sport concussion with near-infrared spectroscopy. Clin. Physiol. Funct. Imaging 2018, 38, 573-585. [CrossRef] [PubMed]

44. Penny, W.; Friston, K.; Ashburner, J.; Kiebel, S.; Nichols, T. Statistical Parametric Mapping: The Analysis of Functional Brain Images; Elsevier: Amsterdam, The Netherlands, 2011.

45. Chiarelli, A.M.; Romani, G.L.; Merla, A. Fast optical signals in the sensorimotor cortex: General Linear Convolution Model applied to multiple source-detector distance-based data. Neuroimage 2014, 85 Pt 1, 245-254. [CrossRef]

46. Perpetuini, D.; Cardone, D.; Filippini, C.; Chiarelli, A.M.; Merla, A. Modelling Impulse Response Function of Functional Infrared Imaging for General Linear Model Analysis of Autonomic Activity. Sensors 2019, $19,849$. [CrossRef]

47. Perpetuini, D.; Cardone, D.; Chiarelli, A.M.; Filippini, C.; Croce, P.; Zappasodi, F.; Rotunno, L.; Anzoletti, N.; Zito, M.; Merla, A. Autonomic impairment in Alzheimer's disease is revealed by complexity analysis of functional thermal imaging signals during cognitive tasks. Physiol. Meas. 2019, 40, 034002. [CrossRef]

48. McCrea, M.; Iverson, G.L.; Echemendia, R.J.; Makdissi, M.; Raftery, M. Day of injury assessment of sport-related concussion. Br. J. Sports Med. 2013, 47, 272-284. [CrossRef]

49. Liebel, S.W.; Clark, U.S.; Xu, X.; Riskin-Jones, H.H.; Hawkshead, B.E.; Schwarz, N.F.; Labbe, D.; Jerskey, B.A.; Sweet, L.H. An FMRI-compatible Symbol Search task. J. Int. Neuropsychol. Soc. 2015, 21, 231-238. [CrossRef]

50. Sun, X.; Zhang, X.; Chen, X.; Zhang, P.; Bao, M.; Zhang, D.; Chen, J.; He, S.; Hu, X. Age-dependent brain activation during forward and backward digit recall revealed by fMRI. Neuroimage 2005, 26, 36-47. [CrossRef] 
51. Poldrack, R.A. Can cognitive processes be inferred from neuroimaging data? Trends Cogn. Sci. 2006, 10, 59-63. [CrossRef]

52. Giza, C.C.; Hovda, D.A. The new neurometabolic cascade of concussion. Neurosurgery 2014, 75 (Suppl. 4), S24-S33. [CrossRef] [PubMed]

53. Macciocchi, S.N.; Barth, J.T.; Alves, W.; Rimel, R.W.; Jane, J.A. Neuropsychological functioning and recovery after mild head injury in collegiate athletes. Neurosurgery 1996, 39, 510-514. [CrossRef] [PubMed]

54. Pujol, J.; Deus, J.; Losilla, J.M.; Capdevila, A. Cerebral lateralization of language in normal left-handed people studied by functional MRI. Neurology 1999, 52, 1038-1043. [CrossRef] [PubMed]

55. Vigneau, M.; Beaucousin, V.; Herve, P.Y.; Jobard, G.; Petit, L.; Crivello, F.; Mellet, E.; Zago, L.; Mazoyer, B.; Tzourio-Mazoyer, N. What is right-hemisphere contribution to phonological, lexico-semantic, and sentence processing? Insights from a meta-analysis. Neuroimage 2011, 54, 577-593. [CrossRef]

56. Saur, D.; Kreher, B.W.; Schnell, S.; Kummerer, D.; Kellmeyer, P.; Vry, M.S.; Umarova, R.; Musso, M.; Glauche, V.; Abel, S.; et al. Ventral and dorsal pathways for language. Proc. Natl. Acad. Sci. USA 2008, 105, 18035-18040. [CrossRef] [PubMed]

57. Black, D.F.; Vachha, B.; Mian, A.; Faro, S.H.; Maheshwari, M.; Sair, H.I.; Petrella, J.R.; Pillai, J.J.; Welker, K. American Society of Functional Neuroradiology-Recommended fMRI Paradigm Algorithms for Presurgical Language Assessment. AJNR. Am. J. Neuroradiol. 2017, 38, E65-E73. [CrossRef]

58. Zaca, D.; Jarso, S.; Pillai, J.J. Role of semantic paradigms for optimization of language mapping in clinical FMRI studies. AJNR Am. J. Neuroradiol. 2013, 34, 1966-1971. [CrossRef]

59. Pillai, J.J.; Zaca, D. Relative utility for hemispheric lateralization of different clinical fMRI activation tasks within a comprehensive language paradigm battery in brain tumor patients as assessed by both threshold-dependent and threshold-independent analysis methods. Neuroimage 2011, 54 (Suppl. 1), S136-S145. [CrossRef]

60. Kaneko, H.; Yoshikawa, T.; Nomura, K.; Ito, H.; Yamauchi, H.; Ogura, M.; Honjo, S. Hemodynamic changes in the prefrontal cortex during digit span task: A near-infrared spectroscopy study. Neuropsychobiology 2011, 63, 59-65. [CrossRef]

61. Hoshi, Y.; Oda, I.; Wada, Y.; Ito, Y.; Yutaka, Y.; Oda, M.; Ohta, K.; Yamada, Y.; Mamoru, T. Visuospatial imagery is a fruitful strategy for the digit span backward task: A study with near-infrared optical tomography. Cogn. Brain Res. 2000, 9, 339-342. [CrossRef]

62. Aleman, A.; van't Wout, M. Repetitive transcranial magnetic stimulation over the right dorsolateral prefrontal cortex disrupts digit span task performance. Neuropsychobiology 2008, 57, 44-48. [CrossRef] [PubMed]

63. Gerton, B.K.; Brown, T.T.; Meyer-Lindenberg, A.; Kohn, P.; Holt, J.L.; Olsen, R.K.; Berman, K.F. Shared and distinct neurophysiological components of the digits forward and backward tasks as revealed by functional neuroimaging. Neuropsychologia 2004, 42, 1781-1787. [CrossRef] [PubMed]

64. Thoma, R.J.; Cook, J.A.; McGrew, C.; King, J.H.; Pulsipher, D.T.; Yeo, R.A.; Monnig, M.A.; Mayer, A.; Pommy, J.; Campbell, R.A. Convergent and discriminant validity of the ImPACT with traditional neuropsychological measures. Cogent Psychol. 2018, 5, 1430199. [CrossRef]

65. Maerlender, A.; Flashman, L.; Kessler, A.; Kumbhani, S.; Greenwald, R.; Tosteson, T.; McAllister, T. Examination of the construct validity of ImPACT computerized test, traditional, and experimental neuropsychological measures. Clin. Neuropsychol. 2010, 24, 1309-1325. [CrossRef]

66. Echemendia, R.J.; Iverson, G.L.; McCrea, M.; Macciocchi, S.N.; Gioia, G.A.; Putukian, M.; Comper, P. Advances in neuropsychological assessment of sport-related concussion. Br. J. Sports Med. 2013, 47, $294-298$. [CrossRef] [PubMed]

67. Jackson, G.D.; Makdissi, M.; Pedersen, M.; Parker, D.M.; Curwood, E.K.; Farquharson, S.; Connelly, A.; Abbott, D.F.; McCrory, P. Functional brain effects of acute concussion in Australian rules football players. J. Concussion 2019, 3, 205970021986120. [CrossRef]

68. Monti, M.M. Statistical Analysis of fMRI Time-Series: A Critical Review of the GLM Approach. Front. Hum. Neurosci. 2011, 5, 28. [CrossRef]

69. Kirilina, E.; Jelzow, A.; Heine, A.; Niessing, M.; Wabnitz, H.; Bruhl, R.; Ittermann, B.; Jacobs, A.M.; Tachtsidis, I. The physiological origin of task-evoked systemic artefacts in functional near infrared spectroscopy. Neuroimage 2012, 61, 70-81. [CrossRef]

70. Erdogan, S.B.; Yucel, M.A.; Akin, A. Analysis of task-evoked systemic interference in fNIRS measurements: Insights from fMRI. Neuroimage 2014, 87, 490-504. [CrossRef] 
71. Rodrigues, A.C.; Lima, M.D.M.; de Souza, L.C.; Furtado, C.; Marques, C.E.; Gonçalves, L.; Lima, M.V.; Lasmar, R.P.; Caramelli, P. No Evidence of Association Between Soccer Heading and Cognitive Performance in Professional Soccer Players: Cross-Sectional Results. Front. Neurol. 2019, 10, 209. [CrossRef]

72. Seidel-Marzi, O.; Ragert, P. Neurodiagnostics in Sports: Investigating the Athlete's Brain to Augment Performance and Sport-Specific Skills. Front. Hum. Neurosci. 2020, 14, 133. [CrossRef] [PubMed]

73. Donders, J.; Stout, J. The Influence of Cognitive Reserve on Recovery from Traumatic Brain Injury. Arch. Clin. Neuropsychol. 2019, 34, 206-213. [CrossRef] [PubMed]

74. Louey, A.G.; Cromer, J.A.; Schembri, A.J.; Darby, D.G.; Maruff, P.; Makdissi, M.; McCrory, P. Detecting cognitive impairment after concussion: Sensitivity of change from baseline and normative data methods using the CogSport/Axon cognitive test battery. Arch. Clin. Neuropsychol. 2014, 29, 432-441. [CrossRef] [PubMed]

75. Yakoub, K.M.; Davies, D.J.; Su, Z.; Bentley, C.; Forcione, M.; Toman, E.; Hammond, D.; Watson, C.N.; Bishop, J.; Cooper, L.; et al. Investigation into repetitive concussion in sport (RECOS): Study protocol of a prospective, exploratory, observational cohort study. BMJ Open 2019, 9, e029883. [CrossRef] [PubMed]

76. Tan, C.H.; Low, K.A.; Kong, T.; Fletcher, M.A.; Zimmerman, B.; Maclin, E.L.; Chiarelli, A.M.; Gratton, G.; Fabiani, M. Mapping cerebral pulse pressure and arterial compliance over the adult lifespan with optical imaging. PLoS ONE 2017, 12, e0171305. [CrossRef] [PubMed]

77. Mathewson, K.E.; Beck, D.M.; Ro, T.; Maclin, E.L.; Low, K.A.; Fabiani, M.; Gratton, G. Dynamics of alpha control: Preparatory suppression of posterior alpha oscillations by frontal modulators revealed with combined EEG and event-related optical signal. J. Cogn. Neurosci. 2014, 26, 2400-2415. [CrossRef]

78. Whalen, C.; Maclin, E.L.; Fabiani, M.; Gratton, G. Validation of a method for coregistering scalp recording locations with 3D structural MR images. Hum. Brain Mapp. 2008, 29, 1288-1301. [CrossRef]

79. Cameron, T.A.; Lucas, S.J.; Machado, L. Near-infrared spectroscopy reveals link between chronic physical activity and anterior frontal oxygenated hemoglobin in healthy young women. Psychophysiology 2015, 52, 609-617. [CrossRef]

80. Carlozzi, N.E.; Kirsch, N.L.; Kisala, P.A.; Tulsky, D.S. An examination of the Wechsler Adult Intelligence Scales, Fourth Edition (WAIS-IV) in individuals with complicated mild, moderate and Severe traumatic brain injury (TBI). Clin. Neuropsychol. 2015, 29, 21-37. [CrossRef]

81. Chiarelli, A.M.; Maclin, E.L.; Low, K.A.; Fabiani, M.; Gratton, G. Comparison of procedures for co-registering scalp-recording locations to anatomical magnetic resonance images. J. Biomed. Opt. 2015, 20, 016009. [CrossRef]

82. Chiarelli, A.M.; Maclin, E.L.; Fabiani, M.; Gratton, G. A kurtosis-based wavelet algorithm for motion artifact correction of fNIRS data. Neuroimage 2015, 112, 128-137. [CrossRef] [PubMed]

83. Sassaroli, A.; Fantini, S. Comment on the modified Beer-Lambert law for scattering media. Phys. Med. Biol. 2004, 49, N255-N257. [CrossRef]

84. Zijlstra, W.G.; Buursma, A.; Meeuwsen-van der Roest, W.P. Absorption spectra of human fetal and adult oxyhemoglobin, de-oxyhemoglobin, carboxyhemoglobin, and methemoglobin. Clin. Chem. 1991, 37, 1633-1638. [CrossRef] [PubMed]

85. Chiarelli, A.M.; Perpetuini, D.; Filippini, C.; Cardone, D.; Merla, A. Differential pathlength factor in continuous wave functional near-infrared spectroscopy: Reducing hemoglobin's cross talk in high-density recordings. Neurophotonics 2019, 6, 035005. [CrossRef] [PubMed]

86. Scholkmann, F.; Wolf, M. General equation for the differential pathlength factor of the frontal human head depending on wavelength and age. J. Biomed. Opt. 2013, 18, 105004. [CrossRef]

87. Dehghani, H.; Eames, M.E.; Yalavarthy, P.K.; Davis, S.C.; Srinivasan, S.; Carpenter, C.M.; Pogue, B.W.; Paulsen, K.D. Near infrared optical tomography using NIRFAST: Algorithm for numerical model and image reconstruction. Commun. Numer. Methods Eng. 2008, 25, 711-732. [CrossRef]

88. Eggebrecht, A.T.; Ferradal, S.L.; Robichaux-Viehoever, A.; Hassanpour, M.S.; Dehghani, H.; Snyder, A.Z.; Hershey, T.; Culver, J.P. Mapping distributed brain function and networks with diffuse optical tomography. Nat. Photonics 2014, 8, 448-454. [CrossRef]

89. Fang, Q.; Boas, D.A. Tetrahedral mesh generation from volumetric binary and grayscale images. In 2009 IEEE International Symposium on Biomedical Imaging: From Nano to Macro; IEEE: Piscataway, NJ, USA, 2009; pp. 1142-1145. 
90. Tian, F.; Liu, H. Depth-compensated diffuse optical tomography enhanced by general linear model analysis and an anatomical atlas of human head. Neuroimage 2014, 85 Pt 1, 166-180. [CrossRef]

91. Tachtsidis, I.; Scholkmann, F. False positives and false negatives in functional near-infrared spectroscopy: Issues, challenges, and the way forward. Neurophotonics 2016, 3, 031405. [CrossRef]

(C) 2020 by the authors. Licensee MDPI, Basel, Switzerland. This article is an open access article distributed under the terms and conditions of the Creative Commons Attribution (CC BY) license (http://creativecommons.org/licenses/by/4.0/). 